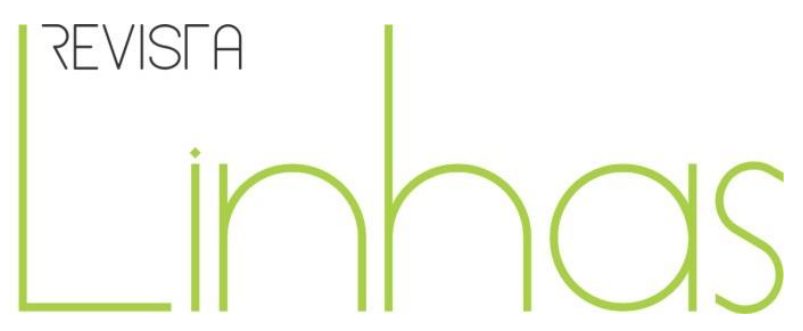

\title{
A hora e a vez dos cadernos escolares como fontes históricas de pesquisa sobre práticas alfabetizadoras
}

\section{Resumo}

Ao considerar que as características físicas, a organização interna e os modos de usos dos cadernos escolares também participam da produção dos discursos materializados em suas páginas, o texto centra-se num estudo da materialidade destes documentos, descrevendo desde os aspectos físicos (formato, dimensões, disposição dos espaços gráficos etc.), a iconografia (capas, organização interna etc.) até os diversos modos de usos e de organização interna de cadernos que se hospedavam silenciosos nas prateleiras dos arquivos pessoais de mães de alunos e de docentes que trabalhavam com turmas do $1^{\circ}$ ao $3^{\circ}$ ano do Ensino Fundamental, no período de 2001 a 2008, em escolas públicas do estado do Espírito Santo. Busca-se, assim, visibilizar os cadernos escolares como fontes históricas de pesquisa, depositárias de discursos acerca do trabalho com a linguagem escrita em classes de alfabetização de crianças, além de ressaltar a importância de preservação e análise destes documentos para a pesquisa em História da Educação.

Palavras-chave: Cadernos Escolares. Fontes Históricas de Pesquisa. Alfabetização.
Fernanda Zanetti Becalli

Instituto Federal do Espírito

Santo - IFES - Brasil

nandazbn@gmail.com

Cleonara Maria Schwartz

Universidade federal do Espírito

Santo - UFES

cleonara@terra.com.br

\section{Para citar este artigo:}

BECALLI, Fernanda Zanetti; SCHWARTZ, Cleonara, Maria. A hora e a vez dos cadernos escolares como fontes históricas de pesquisa sobre práticas alfabetizadoras. Revista Linhas. Florianópolis, v. 18, n. 38, p183213, set./dez. 2017. 


\title{
The time and moment of school notebooks as historical research sources on literacy practices
}

\begin{abstract}
While considering that the physical characteristics, the internal organization and the modes of using school notebooks also participate in the production of speeches materialized in their pages, this text focuses on a study of the materiality of these documents, describing from physical aspects (shape, dimensions, layout of graphic spaces etc.), iconography (covers, internal organization etc.) to different modes of use and of internal organization of notebooks, found silently hosted on the shelves of personal files of students mothers and teachers, who worked with 1st to 3 rd year classes of elementary school, in the period 2001-2008, in public schools in the state of Espírito Santo. We seek, therefore, to make school notebooks visible as historical research sources, repositories of speeches about the work with written language in children's literacy classes, and emphasize the importance of preservation and analysis of these documents for research in Education History.
\end{abstract}

Keywords: School Notebooks. Historical Research Sources. Literacy. 


\section{Enunciações iniciais...}

Os cadernos permaneceram até “[...] a década de 1980” (VIÑAO, 2008, p. 16) esquecidos num canto qualquer. Em Janelas indiscretas: os cadernos escolares na historiografia da educação, Mignot (2010, p. 433) assinala que nem mesmo a Biblioteca Nacional “[...] que tem sob sua guarda impressos registrados em qualquer suporte físico resultante de produção destinada à venda ou à distribuição gratuita", tem dispensado atenção aos cadernos. Diversamente do que se poderia almejar, essa renomada instituição arquiva “[...] monografias, periódicos, publicações em fascículos, fitas cassete, Ips, fitas de vídeo, filmes, CDs, contendo som e/ou imagem, folhetos, livretos e partituras musicais, fotografias, estampas, desenhos, medalhas, mapas, plantas, cartazes", exceto cadernos escolares. E, ainda, complementa "[...] os cadernos escolares não chegam sequer a fazer parte de obras que o Depósito Legal não recebe" porque não eram vistos como fontes históricas de pesquisa.

Diante dessa assertiva, uma questão nos intriga: por que os cadernos não foram guardados em locais nobres, por exemplo, as bibliotecas públicas e/ou escolares? Na perspectiva assinalada pela autora, existem, pelo menos, três razões para esse esquecimento: “[...] a legislação brasileira sobre arquivos escolares; a valorização de documentos tidos como oficiais em detrimento daqueles que tratam da cotidianidade da instituição; a ênfase no estudo da legislação e dos legisladores" (MIGNOT, 2008, p. 7). Vidal (2000, p. 38-39, itálico no original) endossa essa constatação, afirmando que nos arquivos escolares “[...] cadernos de alunos, planos de aula, diários de classe são os primeiros documentos a serem jogados fora do arquivo morto na hora de uma limpeza". Logo, todo “[...] o cotidiano das relações pessoais estabelecidas tende a se perder". Em contrapartida "[...] pilhas e pilhas de Diário Oficial atolam os arquivos, multiplicadas nas unidades escolares".

Em decorrência da ausência de valorização e preservação de cadernos docentes e discentes, produzidos no âmbito escolar, Mignot (2010) ressalta que os pesquisadores têm localizado esses materiais em arquivos pessoais, familiares, públicos e em museus pedagógicos. De igual modo, também localizamos os cadernos e demais suportes de registros escolares que constituem o corpus documental deste estudo em arquivos pessoais de professoras alfabetizadoras e de mães de alunos. 
Embora os cadernos tenham permanecido à sombra, esquecidos no fundo de gavetas, armários e/ou caixas, até, aproximadamente, a década de 80 do século passado, ao analisar a recente historiografia da educação, Mignot (2010, p. 425) relata que o crescente interesse por esse objeto-memória advém de um contexto “[...] marcado por um 'giro memorialístico' que se caracteriza pela valorização da memória individual e coletiva, como uma reação ao 'presentismo'”. Tal assertiva nos permite dizer que a multiplicidade de vozes materializadas nesses documentos possibilita afirmar que os discursos fixados em suas páginas funcionam como um remédio eficaz contra o esquecimento (CUNHA, 2009) permitindo, a qualquer tempo, revisitá-los e, assim, não se esquecer de pessoas, rememorar acontecimentos, rever atividades, dialogar com diferentes escritos e diversos interlocutores em outras situações sociais.

Localizar e dialogar com escritos presentificados em cadernos tem significado um modo de cultivar a memória de pessoas comuns: “[...] alunos/as e professores/as que atuam anonimamente na sala de aula" (MIGONT; CUNHA, 2006, p. 40) e, também, de embrenhar-se no cotidiano de classes de alfabetização para compreender distintos modos de ensinar e aprender praticados ao longo da história da educação e, consequentemente, adentrar em outros tempos escolares, compostos por outros professores e outros alunos, "[...] nem melhores nem piores, mas diferentes" (MIGNOT, 2010, p. 441).

Entendendo, portanto, os cadernos escolares como fontes históricas de pesquisa, depositárias de discursos acerca do trabalho com a linguagem escrita que funcionam como um remédio eficaz contra o esquecimento, direcionamos o olhar para os aspectos físicos (formato, dimensões, disposição dos espaços gráficos etc.), a iconografia (capas, organização interna etc.) e os diversos modos de usos desses documentos. Folhear os 24 cadernos que se hospedavam silenciosos nas prateleiras dos arquivos pessoais de dez docentes que trabalhavam com turmas do $1^{\circ}, 2^{\circ}$ e $3^{\circ}$ ano do Ensino Fundamental, no período de 2001 a 2008, em escolas públicas do estado do Espírito Santo, e de três mães de estudantes, constitui-se em convite para a problematização e a desinvisibilização desses objetos-memória.

Conforme pontua Gvirtz (1999, p. 29, tradução nossa), é preciso desnaturalizar essa fonte histórica de pesquisa porque o “[...] caderno é apresentado [aos alunos] como 
um simples feito. É um elemento óbvio, inquestionável e inviolável", como se, desde o princípio da história das instituições escolares, estivesse presente para documentar os registros escritos e imagéticos fixados em suas páginas por professores e alunos.

No caso francês, Hébrard (2001, p. 118) aponta que o caderno foi "[...] um instrumento comum do aluno de colégio desde o século XVI", tendo sua utilização generalizada a partir da primeira metade do século XIX, "[...] no momento em que o exercício se torna o centro do trabalho escolar de alfabetização", (p. 122) o caderno se ofereceu como suporte físico para a materialização de atividades escolares.

Já no contexto brasileiro, especificamente da capital paulista, Mignot (2008a, p. 80) relata que a presença de cadernos escolares, "[...] em substituição à lousa, no entanto, era mais usual apenas nas salas de aula das escolas da capital daquele estado [São Paulo]. Nas escolas do interior, ela ainda sobreviveu até meados de 1940, demarcando a iniciação do universo das letras". Foi somente quando as grandes empresas caderneiras (Credeal, Jandaia, Tilibra, entre outras) modernizaram seus parques gráficos que o caderno tornou-se acessível financeiramente, por conseguinte, comum aos alunos e transformado em objeto essencial no contexto escolar. Como observa a autora,

Esses suportes de escrita escolar, antes raros, tornaram-se objetos banais, afetando as práticas de escrita, a dinâmica do ensinoaprendizagem, os usos do tempo nas salas de aula. Serviram ao controle de professores sobre alunos, dos diretores sobre os professores, dos inspetores sobre os diretores, das famílias sobre as escolas e as crianças. Superaram a lousa e a folha avulsa. De protagonistas, tornaram-se coadjuvantes dos livros-texto e, posteriormente, dos computadores, nos quais os exercícios são propostos, executados e avaliados. (MIGNOT, 2008a, p. 85)

Seu uso tornou-se tão frequente que não chega a ser debatido ou interrogado, como descreve Santos (2008, p. 145): os pais "[...] de alunos não estranham ou se opõem ao fato de ter de adquirir cadernos no início do ano letivo; professores não se reúnem para decidir se utilizarão ou não cadernos em seu trabalho com os alunos". Ainda que sua presença tenha se tornado óbvia, sua necessidade inquestionável dentro dos contextos escolares e as práticas de registros sejam permeadas pela materialidade desse suporte 
físico, tendo em vista que ela tem suas regras e suas finalidades engendradas socialmente, não é suficiente manusear o caderno para que o aluno aprenda a ocupar o seu espaço, a lidar com a sucessão de folhas ao longo do tempo escolar, com as margens, com o lugar das datas, dos títulos, das tarefas etc. Aprender a usá-lo "[...] constitui-se num aprendizado dirigido e organizado de acordo com determinados procedimentos" (LOPES, 2008, p. 190).

Concordando com a enunciação de Lopes (2008), consideramos que seja papel do professor ensinar à criança aquilo que sabe sobre os cadernos e como usá-los, porque esse objeto não fala, não propõe como pode ser utilizado nem para que serve. Sendo assim, faz-se necessário, no início da vida estudantil, instruir aos alunos que, independente da variedade de modelos e de cores, esse suporte material de registros escolares é formado pela capa, pela contracapa (dura ou flexível) e pelas folhas internas que possuem margens e linhas horizontais com funções específicas.

Tais “[...] características revelam que o manejo de cadernos escolares pressupõe algo mais do que aprender a escrever. Requer, também, o aprendizado de uma organização gráfica" (LOPES, 2008, p. 190-191). Em outras palavras, a escola determina usos específicos dos cadernos, também mediados pela sua materialidade. Sendo assim, é imprescindível ensinar ao aprendiz: a direção convencional da escrita, ou seja, escrevemos e lemos, na língua portuguesa, da esquerda para a direita e de cima para baixo; os textos escritos nos cadernos ocupam a frente e o verso das folhas, sendo que cada atividade deve suceder uma à outra, não podendo saltar páginas; são escritos dentro das margens - linha vertical indicada, geralmente, com a cor vermelha e em cima das linhas horizontais de cor azul; se do lado direito da página, pode-se escrever até o limite marcado pela sombra da linha da margem ou até o final da linha; a lápis ou à caneta. Nas palavras de Toquinho: "Sou eu que vou seguir você do primeiro rabisco até o bê-á-bá [...]", portanto, é o caderno que vai acompanhar o aluno em toda a sua trajetória escolar e, por essa razão, ele precisa aprender a usá-lo.

Marcas desse ensino, ou seja, dessa estrutura peculiar de registros escolares podem estar presentificadas nos cadernos, porquanto os estamos concebendo como “[...] suporte de escrita portador de marcas de quem ensina e de quem aprende. Os registros ali presentes assinalam um percurso da memória escolar e o tornam um 
documento, uma vez que é possível analisar e investigar as condições de sua produção histórica" (LOPES, 2008, p. 190). São, portanto, nas marcas deixadas pelos sujeitos (professoras, alunos e outros envolvidos no contexto escolar) nos cadernos que eles se diferenciam, ainda que sejam de professoras ou de alunos de uma mesma série/ano. Isso equivale a dizer que por meio das marcas inscritas nesses documentos seja possível desnaturalizá-los, tendo em vista que o caderno é um suporte físico convencional que passou a ser considerado como natural nas salas de aula (GVIRTZ, 1999).

Lopes (2008) assevera que a descrição da materialidade do caderno desinvisibiliza esse documento e com Chartier (2007) entendemos que a materialidade do caderno pode ser portadora de sentidos nas relações com os usuários. Seguindo essa linha de pensamento, direcionamos a nossa atenção para a materialidade dos cadernos a fim de evidenciar: são todos do mesmo formato? De quais tamanhos? Formato e tamanho influenciam na escolha? Suas capas possuem (ou não) imagens? Sua escolha pode ter relação com o sexo do/a usuário/a? Como são organizados internamente? Os registros são feitos a lápis, à caneta ou com ambos os instrumentos de escrita? São suportes físicos de outros registros da escrita escolar? Além das atividades diárias, que outros registros estão materializados em suas páginas? Que características são constitutivas desses documentos?

\section{Olhai e vede a beleza da diversidade de registros nos cadernos escolares}

Uma leitura exploratória dos 24 cadernos que constituem o nosso corpus de pesquisa permitiu identificar que 13 são de registros docentes e 11 de discentes. Dentre os de professoras ${ }^{1}$, 11 são cadernos diários, um de textos selecionados de variadas fontes e um de mensagens escritas pelos alunos. Dos cadernos discentes, dez são de registros diários e um de produção de textos.

Todos são de formato retangular. Porém, não são do mesmo tamanho: a maior parte deles, ou seja, 19 cadernos são grandes, medindo os dois lados paralelos verticalmente $27,5 \mathrm{~cm}$ e os outros dois lados paralelos horizontalmente $20 \mathrm{~cm}$. Os outros cinco são pequenos e medem o lado esquerdo e o direito $20,2 \mathrm{~cm}$ de comprimento e 0

\footnotetext{
${ }^{1}$ Os nomes utilizados para identificar as professoras são fictícios.
} 
lado superior e inferior $14,8 \mathrm{~cm}$ de largura. $O$ tamanho desses objetos nos traz indícios de uma preferência das professoras alfabetizadoras pelos cadernos grandes. Dentre os 11 cadernos diários, dez são grandes e dos dez cadernos discentes, nove também são grandes. O que justifica essa predileção?

Basta folhear os cadernos para encontrar uma possível resposta: esses objetos não armazenam apenas registros escritos e imagéticos em suas próprias páginas, a colagem de folhas mimeografadas e/ou xerocopiadas previamente preparadas com fragmentos de atividades copiadas de livros didáticos e/ou de outras coleções, na maioria das vezes, transcritas sem fazer qualquer referência aos autores, é um procedimento recorrente em classes de alfabetização de escolas públicas capixabas. Quer isto dizer que as páginas dos cadernos também funcionam como suportes físicos de outras folhas de papel, ficando a intenção de armazenamento de atividades.

Tivemos a oportunidade de conversar com uma das professoras participantes da pesquisa sobre essa questão e ela nos relatou que

na fase inicial de alfabetização, as crianças não copiam as atividades do quadro com agilidade e isso requer um tempo maior para copiarem e depois realizarem a atividade proposta. Como meu objetivo não é simplesmente a cópia e sim a execução do exercício, também faço uso de atividades nas folhinhas que, posteriormente, são coladas nos cadernos para não perder e ter o registro do que foi realizado naquele dia. A colagem dessas folhas fica melhor em cadernos grandes porque no pequeno é preciso dobrá-las e além de ficar feio cria um volume muito grande no caderno. (DIÁRIO DE CAMPO, 13/03/2011)

Esteticamente, nos cadernos grandes, as folhas coladas ficavam mais bem posicionadas do que nos pequenos. Isso demonstra, entre outras coisas, que a estética na organização interna dos cadernos era, se não primordial, ao menos de grande importância para as professoras alfabetizadoras. Dialogando com o enunciado proferido pela professora, podemos inferir que a utilização de folhas mimeografadas e/ou xerocopiadas, comumente chamadas de folhinhas, minimizava as dificuldades de cópias da lousa e/ou dos livros, por parte dos aprendizes da língua materna, cabendo a eles a realização das atividades propostas e, ao término, colar a folhinha na página do caderno. 
Ainda, observando o exterior dos cadernos, foi possível constatar que é do lado esquerdo que suas folhas são prendidas por costura, grampos ou espiral que permitem a movimentação das páginas. A ficha de identificação individual dos 24 cadernos, preenchida com informações relativas à sua apresentação mais geral, nos possibilitou observar que, independente, da maneira como as folhas são reunidas, elas são soltas e/ou tiradas pelas professoras, pelos alunos e/ou pelos familiares. Uma das professoras relatou que "o pai de uma aluna arrancava as folhas do caderno para fazer cigarro de fumo". (DIÁRIO DE CAMPO, 13/04/2011)

Dentre os dez cadernos docentes que têm suas folhas unidas por grampos ou costuras, o percentual de folhas arrancadas foi de 29\%; essa percentagem diminuiu nos três cadernos de espiral, totalizando 20\% das páginas. Entre os 11 cadernos discentes, sete que têm suas páginas unidas por costura, apresentaram 16\% de folhas arrancadas; essa percentagem aumentou nos quatro cadernos de espiral, chegando a 35\% do total de páginas.

Essas informações podem ser confirmadas no bilhete de uma mãe e/ou responsável, datado de 02/03/2008, em que solicita a contribuição da professora para orientar o filho a ter mais cuidado com o caderno, particularmente, para que ele pare de “cortar" (arrancar) "as folhas do caderno". Nesse caso, os cadernos discentes também cumprem o papel que, normalmente, é desempenhado pela agenda escolar, isto é, meio de comunicação escrita entre a família e a escola. Não encontramos por escrito a resposta da professora na página do caderno. Entretanto, isso não significa que a docente tenha se omitido, tendo em vista que ela pode ter respondido na agenda da criança que a mãe havia solicitado para ser encaminhada para casa diariamente, ter conversado com o aluno sobre o assunto, pedido a ele para falar com a mãe que já conversaram ou falado pessoalmente com a responsável pelo aluno na hora da saída, entre muitas outras possibilidades.

Passeando pelas folhas desse mesmo caderno, localizamos no dia 05/09/2008 uma mensagem de recomendação que estava em sintonia com o mencionado bilhete redigido pela mãe do aluno. Nela, a professora dizia: “Procure caprichar mais!”, uma vez que a página do lado direito havia sido arrancada, possivelmente sem a intenção, e estava colada com fita adesiva. 
Todos os 24 cadernos estavam estremados por uma capa e por uma contracapa. A primeira delimitava o início, marcando a maneira como seus usuários (professoras ou alunos) deveriam posicioná-los para começarem seus registros escritos e/ou imagéticos. Algumas desprovidas de imagens, em que constavam apenas a marca do caderno e algumas linhas para registrar informações sobre o seu proprietário; outras foram encapadas e as donas usaram a técnica da colagem de imagens para personalizá-las.

Também havia capas que traziam impressas imagens de animais ou desenhos do universo infantil que contribuem para tornar o caderno um objeto desejável aos olhos do consumidor. Algumas capas de cadernos discentes possuem etiquetas de identificação, posicionadas sempre no canto inferior direito, constando o nome do aluno, o nome da matéria, a série que cursava e o nome da professora da turma.

Para os usuários, a capa do caderno funciona como "[...] uma espécie de outdoor que revela, em alguns casos, não só a marca do fabricante como também a imagem que se deseja que os colegas tenham sobre ele" (BRAVO, 1997, p. 35, itálico no original). Coadunando com os discursos de Bravo e Fernandes nos artigos intitulados, respectivamente, "Cadernos para todos os momentos" (1995) e "Um marco no território da criança: o caderno escolar" (2008), entendemos que as capas desses objetos também podem refletir o sexo do seu proprietário, pois existem algumas que se direcionam exclusivamente aos meninos e outras às meninas.

Os dois cadernos que pertencem a um aluno do sexo masculino têm estampadas imagens do Batman e dos Transformers - ambos desenhos animados -, enquanto os cadernos de meninas apresentam tons de rosa e são decorados com imagens de Pony, Jolie, Meninas superpoderosas, corações rosa e uma menina pintando as unhas. Outros três, mesmo sendo encapados, ainda guardam marcas do universo feminino - dois cobertos por plástico rosa que contém letras e números e foram identificados com etiquetas autoadesivas da Minnie; e, o outro, apesar de ter sido encapado com papel na cor bege, trouxe colada uma imagem de duas meninas conversando. $O$ único caderno que não foi encapado, embora pareça que se destine a alunos de um ou de outro sexo pelo fato de sua capa ser da cor verde, foi identificado com uma etiqueta autoadesiva da Hello Kitty, evidenciando que sua usuária é uma menina. 
Na contracapa, similar em todos os cadernos, são fornecidas informações sobre os fabricantes, as dimensões do objeto e a quantidade de folhas que variou entre 80 e 200 páginas. Dentre eles, 16 foram produzidos em capa dura e os outros oito em capa flexível. Os de capa dura, geralmente, não foram encapados, porém, os de capa flexível, em sua maioria, foram encapados, possivelmente, para garantir sua durabilidade durante todo o ano letivo.

Ao abrir os cadernos, uma característica comum diz respeito à disposição gráfica interna: folhas pautadas com linhas horizontais que possuem, aproximadamente, oito milímetros de distância entre elas e uma linha vertical à esquerda denominada de margem. A esse respeito, Gvirtz (1999, p. 39), ao trabalhar com cadernos escolares argentinos, concluiu que apesar de a margem e o centro da folha apresentarem funções específicas, “[...] a atividade escolar ressignifica e dá novos sentidos a essas palavras, assim como dá também outras possibilidades a esses espaços”.

De modo semelhante, observamos que o espaço da margem segue combinações partilhadas pelos usuários: não apenas delimita o espaço reservado para o início dos registros diários realizados pelos alunos - na língua portuguesa, convencionalmente, escrevemos da esquerda para a direita e de cima para baixo -, como também pode materializar, em sua parte externa, comentários e observações das professoras.

Os registros escritos materializados nos cadernos discentes evidenciam que ao aprendiz da língua materna não é permitido escrever antes da margem; suas escritas devem se posicionar no espaço interno da folha e estar alinhadas sobre as linhas horizontais do caderno. Contudo, as enunciações realizadas pelas professoras podem ultrapassar essa linha vertical e serem escritas horizontal ou diagonalmente.

Isso deixa claro que há regras, mas nem todas são cumpridas por todos os atores do ambiente escolar, tendo em vista que as docentes para registrarem seus comentários podem, até mesmo, justapor às suas escritas as escritas discentes, por exemplo, a letra $C$ com sua parte inferior alongada indicando que a cópia da família silábica "ba-be-bi-bo-bu" e das palavras “Bibi, Bia, babá, boi” estava correta. Ou seja: as professoras transgridem, não respeitando as normas que ensinam para seus alunos e que regulam o uso dos espaços internos dos cadernos. 
Esse exercício de folhear e ler, página por página, dos cadernos em pauta nos permitiu visualizar outro elemento da estrutura de registros escolares: a marcação do tempo. Bakhtin (2003, p. 225) pontua que o tempo se manifesta

[...] acima de tudo na natureza: o movimento do sol, das estrelas, o canto dos galos, os objetos sensoriais, visíveis das estações do ano; tudo isso, em uma relação indissolúvel com os respectivos momentos da vida humana, dos costumes, da atividade (do trabalho), constitui o tempo cíclico em um grau variado de intensidade. $O$ crescimento das árvores, do gado, a idade das pessoas são sinais visíveis de períodos mais longos.

E como o tempo se mostra nos cadernos escolares? Materializada de diferentes modos, a anotação da data marca o dia, o mês e o ano em que determinadas atividades foram realizadas e, geralmente, se faz presente no início das páginas. Em alguns casos, o registro da data veio acompanhado do nome da escola ou do dia da semana; em outros, é acrescido o nome do usuário. As variações existentes no modo de registro proposto e exigido, supostamente dependem de questões institucionais e/ou de preferências do professor alfabetizador.

Aparentemente, datar as atividades planejadas pelos professores e realizadas pelos alunos, parece um fazer óbvio e inquestionável. Contudo, a presença da data permite conceber o caderno como uma unidade temporal que materializa registros diários e sistemáticos de um tempo vivido entre professores e alunos e alunos e alunos. Mas, o que define essa temporalidade? A partir de 1996, a Lei de Diretrizes e Bases da Educação Nacional n. 9394, institui, em seu artigo 24, inciso I, que “[...] a carga horária mínima anual será de oitocentas horas, distribuídas por um mínimo de duzentos dias de efetivo trabalho escolar, excluído o tempo reservado aos exames finais, quando houver".

Portanto, a marcação desse tempo socialmente instituído para as atividades escolares compreende o período de um ano letivo e serve a diferentes sujeitos professores, pedagogos, diretores, alunos, pais e/ou responsáveis, pesquisadores, entre outros, para identificar a organização do trabalho com a linguagem em classes de alfabetização, bem como a realização (ou não) das atividades propostas. Na visão de Santos (2002, p. 94-95), essa prática de “[...] preceder com a data a qualquer atividade escrita no caderno dá a ele o lugar de relógio e o status de documento", permitindo, 
assim, conhecer "[...] o itinerário de cada criança, série ou professor, em nível de tempo e produção". Contudo, cabe ressaltar que nenhum dos cadernos em questão materializou registros referentes aos 200 dias letivos; em outras palavras, não presentificaram registros do primeiro ao último dia de aula, simplesmente, porque nem todos os afazeres em sala de aula estão nos cadernos. Como nos alerta Viñao (2008, p. 26),

\begin{abstract}
[...] os cadernos não refletem nem dizem nada sobre os tempos improdutivos ou intervalos entre uma e outra tarefa. Também não informam sobre o que os demais alunos fazem ao mesmo tempo em que o aluno escreve, desenha ou faz contas ou sobre o que o professor faz, em especial quando se desloca entre as mesas vendo e controlando o que os alunos estão fazendo, dando tarefas ou deveres a algum deles, resolvendo dúvidas, intervindo em alguma conversação ou iniciando-a, fazendo indicações corretoras sobre o andamento etc., ou seja, combinando o ensino individual com o simultâneo a toda a turma ou a diferentes grupos dela.
\end{abstract}

Desse modo, os cadernos coletados e arquivados em nosso banco de dados materializam somente parte do tempo vivido em classes de alfabetização, assim, discordamos parcialmente do apontamento feito por Santos (2002), pois entendemos que esses documentos podem nos possibilitar enxergar apenas parte do itinerário de cada criança, série ou professor, em nível de tempo e produção. Essa é uma das limitações que deve estar clara para os pesquisadores que se debruçam sobre os cadernos - nem todas as atividades diárias da turma são registradas no caderno.

Ainda coube-nos indagar: a quem era consentido escrever a lápis? E à caneta? Ou com ambos os instrumentos? A maioria das professoras escrevia à caneta enquanto as/o alunas/o faziam seus registros a lápis. Possivelmente, a criança, em fase de alfabetização, escrevia a lápis pela flexibilidade que o grafite propõe, sendo possível voltar, apagar com a borracha e escrever novamente, ao contrário da rigidez da escrita à caneta. Outra possibilidade levantada por Lopes (2008, p. 195) é de que a cor utilizada pelo professor deve ser diferente daquela usada pelo aluno para "[...] valorizar o contraste que distingue a resposta da correção. Essa característica também parece contribuir para direcionar o olhar mais para a marcação do que para o registro do aluno". Já em seus cadernos de 
planejamentos diários, as professoras usavam livremente canetas de cores variadas assim como o lápis.

As vozes das professoras também se fizeram presentes nos cadernos das crianças através de registros que foram sendo inscritos diariamente, sob a forma de correções dos trabalhos realizados. De acordo com Lopes (2008, p. 192), as marcas de correção simbolizam uma relação construída entre os docentes e os discentes no processo discursivo da linguagem escrita que se desencadeia dentro dos espaços das salas de aula e se vincula

[...] às relações de poder. Em primeiro lugar, porque expressam o que é correto ou não em determinado contexto; e, em segundo, porque assinalam a hierarquia das relações entre quem ensina e quem aprende. Entre outras funções, elas intencionam não só indicar uma ordem, mas também dirigir a atenção para aspectos relacionados aos diversos eventos que compõem o cotidiano escolar. $O$ que se sabe sobre a atividade de correção escolar faz parte de uma rede de sentidos sociais e integra um saber sobre papéis e atividades docentes.

Por meio dessas marcas foi possível distinguir três formas de diálogos docentes: a) elogios: “Ótimo! Lindo! Excelente! Parabéns! Joia! Ok! Maravilha! Show! Parabéns quanto mais te conheço mais te amo! Beijos! Parabéns você está cada dia melhor!”; b) comprovação da revisão feita na atividade: a letra $V$ ou a palavra Visto!, em alguns casos, seguida da data; e, c) recomendações: "Não cumpriu com o dever de casa. Falta observar um pouquinho a escrita das palavras no quadro. Procure caprichar a letra e o caderno. Cabeçalho é feito em casa".

São as vozes de professoras alfabetizadoras, materializadas em tinta e papel, oferecendo aos interessados - pais, pedagogos, diretores, familiares, amigos, pesquisadores etc. uma possibilidade de acompanhar o vivido e o valorado no interior das salas de aula, tendo em vista que as mencionadas inscrições qualificam ou desqualificam o desempenho dos discentes na realização das atividades, apontando o que estava correto ou o que precisava melhorar, e, ainda, permitem verificar se o professor alfabetizador acompanhava, individualmente, cada um de seus alunos. Nas palavras de Lopes (2008, p. 195), 
a família, por meio das marcas de correção, também controla as ações do professor, já que elas informam aos pais que ele acompanha o percurso do aluno sistematicamente. [...] a comunidade vigia a atividade docente ao olhar para os indicadores de correção e, desse modo, verifica se o professor vem acompanhando cada um dos alunos em todas as atividades.

A título de exemplo, quando os pais e/ou responsáveis pelo aluno Christony leram a mensagem que foi escrita pela professora em seu caderno - "Parabéns Estou muito orgulhosa de você. Beijocas", no dia 24/09/2008, souberam que o menino apresentou, na realização daquela atividade (cópia da agenda do dia), um desempenho esperado. Ao contrário do momento em que os pais e/ou responsáveis da aluna Luíza viram a mensagem: "Lindinha você está muito fofa nas aulas, só precisa prestar atenção na cópia das palavras do quadro, tá bom... Sucesso. Te amo muito e Jesus também!", datada de 13/06/2007, eles tiveram ciência que ela é considerada uma boa aluna, entretanto, por algum motivo, não prestou atenção na cópia das palavras e, assim, poderiam estabelecer um diálogo com a professora sobre o comportamento da menina em sala de aula.

Os diálogos docentes com outros interlocutores - alunos, pais e/ou responsáveis nos induziram a considerar uma das características essenciais do enunciado, proposta por Bakhtin (2003, p. 289): “[...] a relação do enunciado com o próprio falante (autor do enunciado) e com outros participantes da comunicação discursiva”. Conforme já sabido, todo enunciado, assim como um elo na corrente da comunicação discursiva, responde a enunciados antecedentes e potencializa respostas futuras. Isso porque, de acordo com o autor,

ao construir o meu enunciado, procuro defini-lo de maneira ativa; por outro lado, procuro antecipá-lo, e essa resposta antecipável exerce, por sua vez, uma ativa influência sobre o meu enunciado [...]. Ao falar, sempre levo em conta o fundo aperceptível da percepção do meu discurso pelo destinatário: até que ponto ele está a par da situação, dispõe de conhecimentos especiais de um dado campo cultural da comunicação; levo em conta as suas concepções e convicções, os seus preconceitos (do meu ponto de vista), as suas simpatias e antipatias tudo isso irá determinar a ativa compreensão responsiva do meu enunciado por ele. (BAKHTIN, 2003, p. 302) 
Nessa perspectiva, podemos afirmar que o direcionamento a alguém é uma particularidade constitutiva do discurso sem o qual não haveria enunciado e sim palavras, frases, orações de ninguém para ninguém. Exemplificando, esse direcionamento de que nos fala Bakhtin (2003) foi registrado no caderno de um aluno da $1^{\text {a }}$ série em que a professora relatou sobre a confecção de um livro que havia sido produzido pelos próprios alunos, após visita ao Projeto Tamar, e, seguidamente, convidou os familiares a registrarem, por meio da escrita, suas opiniões acerca do processo de aprendizagem das crianças e do trabalho realizado pela escola.

O diálogo escrito evidenciou a utilização do caderno escolar como uma ponte de mão dupla lançada entre a professora e a família da criança que, num extremo, se sustentou no relato docente e, no outro, se apoiou na opinião dos pais. Assim, a professora “[...] não espera uma compreensão passiva, por assim dizer, que apenas duble o seu pensamento em voz alheia, mas uma resposta, uma concordância, uma participação, uma objeção, uma execução, etc." (BAKHTIN, 2003, p. 272), visto porque ao produzir seu enunciado, requereu o posicionamento dos pais e/ou responsáveis pela criança, esperando que eles compreendessem o que foi escrito e, dessa maneira, pudessem oferecer suas contrapalavras.

Embora os interlocutores - "Senhores pais e/ou responsáveis", a quem foi direcionado o discurso, não estivessem presentes para a instauração imediata do diálogo, por dois motivos ponderamos que relações dialógicas foram instituídas: primeiro, seguindo a orientação bakhtiniana, o simples fato de ser ouvido, escutado, por si só, já estabelece uma relação dialógica. No caso supracitado, como o pai respondeu à enunciação, podemos dizer que o discurso da professora foi acolhido por ele.

Em segundo lugar, “[...] pode-se compreender a palavra 'diálogo' num sentido amplo, isto é, não apenas como a comunicação em voz alta, de pessoas colocadas face a face, mas toda comunicação verbal, de qualquer tipo que seja" (BAKHTIN; VOLOCHINOV, 2004, p. 123). Desse modo, os enunciados escritos tanto pela professora quanto pelo pai acabaram entrando nessa mesma engrenagem dialógica, uma vez que transitaram de um locutor ao outro em busca de respostas, como aponta o pensador russo, "[...] o locutor termina seu enunciado para passar a palavra ao outro ou para dar lugar à compreensão responsiva do outro." (BAKHTIN, 2003, p. 275). 
Por ter clareza de quem era sua interlocutora naquele contexto enunciativo, o pai de Chrystoni escolheu um vocabulário que certamente agradou a alfabetizadora: “Meus parabéns o tema escolhido foi um grande aprendizado para todos nós". Todavia, consideramos que a delimitação de linhas, por parte da professora, pode ter limitado a escrita, por exemplo, ao afirmar que "todos nós aprendemos muito sobre as tartarugas", o responsável pelo aluno não mencionou quais foram, de fato, os conhecimentos aprendidos. Mesmo assim, podemos inferir que nessa situação de comunicação a língua se tornou viva, tendo em vista que se concretizou através de enunciados dos interlocutores ao demonstrarem uma compreensão responsiva de diálogo, em que o outro se tornou falante e vice-versa.

Os cadernos docentes também não se circunscrevem aos registros escritos de planejamentos diários das atividades a serem propostas aos alunos, sendo utilizados como documentos comprobatórios de reuniões realizadas no âmbito escolar. É o caso de uma reunião de pais, realizada no dia 23/05/2006, cuja ata foi registrada no caderno. Trata-se de uma demonstração do comprometimento da professora em contribuir para resolver um problema que interferia diretamente no processo ensino e aprendizagem - a sala de aula superlotada.

Apesar de a reunião versar sobre um assunto de interesse da instituição escolar e da família - o excesso de alunos em sala de aula -, apenas quatro mães compareceram. Também é possível levantar a hipótese de que nem todos os responsáveis pelos cinco alunos que iriam mudar de classe, por uma ordenança da Secretaria Municipal de Educação de Vargem Alta, estiveram presentes.

Numa reunião posterior com as turmas das duas professoras que trabalhavam com o Pré $11 / 1^{\circ}$ ano, datada de 06/06/2006, localizamos o registro da presença de sete mães e/ou responsáveis, sendo que somente uma delas compareceu às duas reuniões. Assim, os cadernos docentes também nos dão indícios da participação dos pais e/ou responsáveis na vida acadêmica dos filhos.

Os registros também contribuem para “[...] desconstruir a crença de que os/as profissionais responsáveis por ensinar a ler a escrever, não escrevem" (MIGNOT; CUNHA, 2006, p. 42). O que os professores não escrevem? Eles podem não escrever diariamente com o propósito de publicação. Dentre as 14 docentes participantes da pesquisa, todas 
afirmaram, em questionário, ter escrito, por exemplo, o Trabalho de Conclusão de Curso da Graduação, a Monografia da Especialização e uma escreveu a Dissertação de Mestrado. Esta foi a única docente que declarou escrever artigos para apresentação em congressos e/ou para a publicação em periódicos especializados. As demais costumam apresentar os trabalhos desenvolvidos com as crianças em Mostras Culturais, Feiras realizadas nas próprias escolas e/ou nas Secretarias Municipais de Educação.

Conforme apontam Mignot e Cunha (2006), no texto Razões para guardar: a escrita ordinária em arquivos de professores/as, no espaço interdiscursivo das instituições escolares, de interação com os outros, os profissionais da educação

[...] corrigem os cadernos dos alunos deixando palavras de estímulo e reprimenda, mandam recados para os pais para comunicar sobre o rendimento dos filhos, lembrar uma festa, cobrar um livro, informar as faltas, solicitar encaminhamentos médicos, entre muitas razões. Os/as professores/as também fazem diários nos quais anotam o conteúdo trabalhado, as presenças dos alunos e observações diversas.

Preenchem formulários. Fazem relatórios. Lançam notas. Elaboram fichas de observação. (MIGNOT; CUNHA, 2006, p. 52)

Enfim, os professores escrevem! Seja para relatar, solicitar, controlar, esclarecer, confirmar, recomendar, questionar e/ou desabafar etc. Outra prática que ressalta a leitura dos cadernos docentes é a utilização desse objeto como agenda, assumindo a função de guardar datas importantes, registrar acontecimentos locais, tarefas a serem realizadas, entre outras. A escola, as professoras e os pais escrevem e/ou colam bilhetes de natureza diversa nos cadernos, seja para avisos de cunho administrativo, informes de visitas extraescolares, alterações nas atividades cotidianas, desempenho de alunos, colaboração mensal para reprodução de folhas xerocopiadas e assim por diante.

No caderno da professora Letícia foi possível observar, na página do lado esquerdo, um bilhete informando aos pais e/ou responsáveis pelas crianças que no dia 18/09/2006 não haveria aula porque as professoras estariam estudando na Secretaria Municipal de Educação. O bilhete mantém esse elo na situação concreta de comunicação escrita. Breves, objetivos e com linguagem simples, colados em cadernos docentes e 
discentes, esse gênero discursivo foi constantemente utilizado pelas professoras e pelo corpo técnico-administrativo da esfera escolar.

Bakhtin (2003, p. 283) nos permite compreender que sempre emolduramos o nosso discurso em forma de gêneros elaborados por gerações anteriores sem os quais as atividades comunicativas humanas tornar-se-iam praticamente irrealizáveis. Nas palavras do autor, se "[...] os gêneros do discurso não existissem e nós não os dominássemos, se tivéssemos de criá-los pela primeira vez no processo do discurso, de construir livremente e pela primeira vez cada enunciado, a comunicação discursiva seria quase impossível".

Comunicamo-nos verbalmente por certo gênero discursivo porque as manifestações verbais ocorrem por meio de textos "[...] concretos e únicos, proferidos pelos integrantes desse ou daquele campo da atividade humana" (BAKHTIN, 2003, p. 261). Como defende o pensador russo, é nas esferas de utilização da língua que os seres humanos elaboram tipos relativamente estáveis de enunciados, denominados de gêneros discursivos, que se manifestam em forma de textos em variados suportes. A eleição de certo gênero realizada pelo falante não é totalmente livre e sim

[...] determinada pela especificidade de um dado campo da comunicação discursiva, por considerações semântico-objetais (temáticas), pela situação concreta de comunicação discursiva, pela composição pessoal dos seus participantes, etc. A intenção discursiva do falante, com toda sua individualidade e subjetividade, é em seguida aplicada e adaptada ao gênero escolhido, constitui-se e desenvolve-se em uma determinada forma de gênero. (BAKHTIN, 2003, p. 282)

Cada situação de comunicação acontece em condições determinadas e com finalidades específicas, o que produz marcas nos três elementos que estão imbricados nos gêneros: o conteúdo (tema), o estilo verbal (seleção de recursos da língua) e a construção composicional. Ao interagirmos com os outros sujeitos através da linguagem, produzimos enunciados que são contextualizados, circunscritos a situações específicas e repletos de intencionalidade. Portanto, a escolha do gênero não é aleatória, mas está intrinsecamente relacionada com a situação concreta de comunicação, o tema e a intenção do falante. 
Com a finalidade de comunicar que no dia 18/09/2006 não haveria aula porque as professoras iriam participar de um curso na Secretaria Municipal de Educação (Semed), de Vargem Alta (ES), Letícia elegeu o gênero bilhete para informar aos pais e/ou responsáveis pelas crianças. Embora tenha uma estrutura relativamente livre, a presença ou não das marcas características desse gênero discursivo (destinatário, remetente, mensagem e localização espaço temporal) dependem, entre outros fatores, do grau de afetividade entre destinatário e remetente, assim como do objetivo a ser alcançado.

Por se tratar de um bilhete institucional, a docente registrou a localização espacial - Escola Pré-Escolar Boa Esperança, porém não fez referência à data em que produziu aquele texto, ficando subentendido que o bilhete havia sido escrito no dia em que foi colado no caderno das crianças (15/09/2006); e, para se dirigir aos seus interlocutores fez uso do pronome de tratamento Senhores, mas a quais senhores se direcionou? Aos pais ou responsável pelos alunos que cursavam o Pré II/1 $1^{\circ}$ ano. A mensagem a ser transmitida no dia 18/09 não haverá aula, foi acompanhada de uma justificativa que apontou por qual razão não haveria aula para as crianças, ao mesmo tempo em que informou a família onde os docentes estariam naquele dia de trabalho (segunda-feira) - pois os professores estarão fazendo um curso na SEMED. E, por fim, na despedida, a professora fraternalmente agradece a atenção dos pais e/ou responsáveis - “Desde já agradeço a sua atenção", porém, não assinou o bilhete.

Em respeito à organização familiar, ela encaminhou o bilhete no dia 15/09/2006, permitindo, assim, que os pais estabelecessem com a antecedência de dois dias com quem as crianças ficariam, uma vez que não estariam na escola naquele determinado horário (matutino ou vespertino). E, na página do lado direito, ela escreveu com letras grandes na cor vermelha a data da capacitação, de modo que o não cumprimento desse compromisso não poderia ser justificado pelo esquecimento. Esse registro permite considerar que os cadernos também eram usados como objetos mnemônicos, ou seja, que não a deixavam esquecer-se de estudos, reuniões, entre outros compromissos docentes.

Por essa razão, também nos referimos ao caderno como objeto-memória. Nesse caso específico, ao voltar e ler os registros supracitados, a professora pode rememorar se os responsáveis pelas crianças apoiavam a participação docente em cursos dessa 
natureza; se todos os pais leram o bilhete ou se na segunda-feira (18/09) compareceram alguns alunos na escola; com qual frequência esses encontros eram realizados na SEMED; quem ministrou a capacitação; quais colegas de trabalho estavam presentes; quais discussões foram desencadeadas nessa reunião; entre outras lembranças com riqueza de detalhes ou sem muitas nuances. Assim, o caderno diário "[...] Ihe dá perenidade contra a fatalidade do esquecimento" (CUNHA, 2009, p. 253).

Ainda cumprindo a função de objeto mnemônico, as professoras escreviam lembretes nas páginas de seus cadernos. Tais observações, na maior parte das vezes, foram registradas separadamente do planejamento das atividades, posicionadas à direita da atividade ou no espaço das margens da folha, e o modo como foram escritas - em diagonal, não respeitando as linhas horizontais da página. Esses lembretes se referiam à entrega de livros didáticos, entrega de materiais de limpeza, datas de avaliações, rendimento de alunos, reunião de pais, período de recesso, comemorações de aniversários, entre muitos outros.

Em um dos registros, a professora Elaine não poderia esquecer de enviar os livros didáticos para a casa dos alunos, a fim de que os pais e/ou responsáveis pelas crianças encapassem os mesmos; assim, registrou em meio ao planejamento do dia 03/03/2004 “Entrega dos livros didáticos p/ serem encapados”. Pela marcação do tempo, materializada por meio da data no alto da página, observamos que era o início do ano letivo e essa solicitação à família demonstrava o cuidado que os alunos deveriam ter para garantir um bom estado de conservação dos livros.

Por se tratar de livros didáticos usados por alunos que cursavam a $1^{\text {a }}$ série do Ensino Fundamental, portanto, livros considerados consumíveis pelo Programa Nacional do Livro Didático (PNLD), eles não precisavam ser devolvidos à instituição escolar para a utilização por outros alunos nos dois anos subsequentes, porém os aprendizes iriam utilizá-los no decorrer de todo o ano letivo de 2004, assim, necessitavam ser conservados.

Sobre a utilização de livros didáticos de alfabetização em salas de aula, a professora Luciene fez a seguinte afirmação na escritura do questionário: 
Nas classes de $1^{\text {a }}$ série, em que a maioria dos alunos estão aprendendo a ler e a escrever, só utilizo o livro didático a partir do $2^{\circ}$ semestre porque as atividades dos livros são muito complexas para as crianças na fase inicial de alfabetização, não correspondem a realidade deles, pois os textos são muito longos. No início do ano costumo trabalhar com textos que as crianças sabem de cor - parlendas, adivinhas, poemas, entre outros, e uso xerox de atividades para que elas não fiquem copiando do quadro. (QUESTIONÁRIO, 16/08/2011)

Um bilhete colado, no canto direito da página do caderno docente, aponta para essa utilização de folhas xerocopiadas. Embora a docente trabalhe numa escola pública, na qual as crianças recebem gratuitamente livros didáticos do Governo Federal que são escolhidos pelas próprias regentes de classe, ela solicitou a colaboração dos pais, enviando, mensalmente (de março a dezembro), um real para a xerox de atividades.

Essa ocorrência nos suscitou alguns questionamentos: como se dá o processo de escolha dos livros didáticos de alfabetização em escolas municipais e estaduais do Espírito Santo? Por que as professoras, a cada três anos, elegem, dentre os livros que já foram escolhidos e, consequentemente, aprovados pelo MEC, aqueles que consideram apropriados na área de alfabetização e acabam fazendo uso de folhas xerocopiadas? 0 que isso nos indica? A primeira opção escolhida pelas professoras chega às escolas? As atividades xerocopiadas são retiradas de quais materiais didáticos? Não nos detemos em buscar possíveis respostas para tais questões porque entendemos que elas abrem possibilidades para estudos futuros acerca dos processos de escolha, de distribuição, e, até mesmo, de apropriações e usos de livros didáticos em classes de alfabetização de escolas capixabas.

Apesar de certa resistência em relação aos livros didáticos de alfabetização, de outro lado, dialogamos com professoras que os consideram indispensáveis em seus fazeres profissionais, conforme enuncia a professora Simone:

Na escola onde trabalho o livro adotado é o Porta Aberta, gosto muito desse livro por sua apresentação gráfica, pela disposição espaçada dos textos nas páginas e porque as atividades propostas condizem com o nível de aprendizagem dos meus alunos. Para muitas das minhas crianças esse é o primeiro e, talvez, o único livro que elas recebem, por isso não tenho o direito de guardar no armário. Não fico presa somente a ele, seguindo como o único roteiro de trabalho, também faço uso de outros 
livros para preparar as aulas, mas sempre os utilizo em sala de aula. (QUESTIONÁRIO, 17/11/2011)

Retomando a função dos cadernos diários como objetos mnemônicos, a professora Elaine também registrou, a lápis, no canto superior direito da página, a semana de recesso no mês de julho. “Um período de descanso!" Apesar de a enunciação nos permitir observar que as férias iniciaram no dia 23/07, podemos notar que essa data se referia somente aos alunos, pois para as docentes esse foi um dia de estudo promovido pela Secretaria Municipal de Educação de Pinheiros: “De 23/07 a 01/08 estaremos em recesso. 23/07 estudo no Lions".

As docentes também registram acontecimentos locais em seus cadernos. Exemplificando, a professora Simone registrou que no sábado (12/04/2003), precisamente às 16h, um forte vento levou parte do telhado da Escola Canudos e de várias residências. A cor da caneta nos oferece indícios de que o registro foi feito juntamente com o planejamento da segunda-feira, porque o da sexta-feira anterior tinha sido realizado na cor azul. Ainda é possível inferir que esse acontecimento não interferiu no andamento das aulas, tendo em vista que no dia 14/04 (segunda-feira) a professora não fez nenhuma anotação sobre o cancelamento das atividades.

Já a professora Vanda escreveu uma observação, em 30/10/2006, usando caneta de cor vermelha: "Velório de Ritieli vizinha da escola". Especificamente, naquela data não consta o registro das atividades que seriam trabalhadas com as crianças da $1^{\text {a }}$ série, portanto, essa ausência de registro do planejamento diário é um indício de que não houve aula na última segunda-feira de outubro daquele ano, por motivo de falecimento de uma pessoa que residia próxima à escola em que lecionava.

Embora não pudessem viver a dor do outro, ou seja, não pudessem se colocar integralmente no lugar daqueles que tiveram os telhados de suas casas arrancados pela força do vento ou dos que perderam uma pessoa da família porque, conforme postula Bakhtin (2003, p. 24, itálico no original), quando “[...] me compenetro dos sofrimentos do outro, eu os vivencio precisamente como sofrimentos dele, na categoria do outro, e minha reação a ele não é um grito de dor e sim uma palavra de consolo e um ato de ajuda". As enunciações das professoras alfabetizadoras materializadas nos cadernos 
diários nos dão indícios de que elas compartilharam dos seus lugares o sofrimento de pessoas que viviam nos arredores da escola. O fato de não ter havido aula no dia 30/10/2006 pode ser considerado como uma palavra de consolo, pois, possivelmente, a professora esteve presente naquele velório e, talvez, alguns de seus alunos e dos pais, para se solidarizarem com aqueles que sofreram a dura dor da morte.

Não foram somente acontecimentos desagradáveis como desastres da natureza e falecimentos que as professoras escreveram em seus cadernos. A professora Elaine registrou um piquenique com seus alunos, num dia de sábado, em uma fazenda da região. Um momento de confraternização no final do ano letivo de 2004 !

Os registros materializados nos cadernos também nos permitiram ver que "[...] não há uma escrita íntima que não tenha a dimensão da vida profissional, nem uma escrita profissional que não tenha a dimensão da vida pessoal" (MIGNOT, 2008, p. 103). Ao deixar marcas da presença de professores substitutos, seja através do registro escrito feito pela própria professora que na quinta-feira teria um substituto, ou de um recado que a substituta tenha deixado para a professora regente de classe, contemplamos esse entrelaçamento da vida profissional com a vida pessoal.

O tempo diário que ambas as professoras destinavam ao trabalho nas instituições escolares de Ensino Fundamental indica que cumpriam uma carga horária de 50 horas semanais ministrando aulas, o que significa ministrar aulas em dois turnos (matutino e vespertino), fora as horas direcionadas ao planejamento de atividades que, na maioria das vezes, é realizado em casa. A professora Luciene nos relatou que trabalhava em escolas diferentes do município de Cachoeiro de Itapemirim e que "o horário de intervalo de uma escola para a outra (11h3ominh às 13h) se restringe ao deslocamento e ao almoço, caso tenha que resolver alguma questão particular dentro do horário comercial fico sem almoçar" (DIÁRIO DE CAMPO, 10/05/2011).

Não podemos desconsiderar que assumir diversas jornadas de trabalho e, por conseguinte, ter um escasso tempo para descanso são situações que interferem nos afazeres profissionais docentes, produzindo cansaço e desgaste (físico, emocional etc.). Dentre as possíveis razões de âmbito pessoal que podem justificar a ausência das professoras em salas de aula, mencionamos: problemas de saúde, questões familiares, falta de tempo para resolver problemas cotidianos, desencantamento com a profissão 
etc. Diante desse quadro profissional, uma das soluções encontradas pelas professoras foi lançar mão do professor substituto para que os alunos não ficassem sem aulas. Ainda localizamos registros em que os alunos da $1^{\mathrm{a}}$ série foram dispensados porque a professora precisou faltar.

Os cadernos docentes também materializam outros dilemas vivenciados pelas professoras em seus fazeres profissionais e pelos alunos. Dentre eles, nos chamou a atenção 30 observações sobre o comportamento de um único aluno que foram registradas por uma docente, no decorrer do ano letivo de 2006. Essas enunciações apontavam para a não realização de atividades em sala de aula: “Luís F. se recusa a estudar e chama a prof Idiota” (14/03); não realização de tarefas de casa: “L. Fernando não fez o dever de casa na cartilha" (15/03); conversa com os pais: "Zeacir passou na Escola e conversei sobre Luis Fernando" (17/03), "Sueli veio à escola conversar situação de Luís Fernando" (20/04); acompanhamento do pai em sala de aula: “Após veio Zeacir e ficou na sala acompanhando seu filho Fernando" (20/04); xingamentos: "Luis Fernando se recusa em estuda / Xinga a professora e da soco e ponta-pé na professora" (08/08); conversa com uma representante da Secretaria de Educação: “Conversa Vera (Secretária Educação); comportamento desde 14/3/06; xingamento; “comportamento explosivo (chute e soco)" (15/08); idas ao médico: “Fernando foi ao Psicólogo" (17/08); entre muitas outras. Vale ressaltar que no último dia de aula (21/12) a professora encerrou os escritos naquele caderno com o seguinte registro na cor vermelha: "Obrigado Senhor por mais um ano".

Outra professora pediu misericórdia a Deus - registro escrito a lápis no alto da página do caderno. Possivelmente, aquela sexta-feira (06/06/2008) estava sendo um dia difícil, vivenciava algum problema, seja de ordem profissional - pois os registros indicam que na aula de Educação Física a professora ficou com cinco alunos em sala para tomar a leitura e dois deles só liam palavras simples, um apresentou dificuldade na leitura de todas as palavras e as outras duas tiveram um bom desempenho; ou, seja de ordem familiar etc.

Longe de serem supérfluos, os discursos das referidas professoras alfabetizadoras oferecem informações sobre as tensões e as contradições que perpassam seus fazeres profissionais. Embora no caderno diário a ênfase recaia na organização do trabalho em 
classes de alfabetização, foi possível encontrar menções ao desenvolvimento e ao comportamento de alunos, ao acompanhamento dos pais, ao apoio de funcionárias da Secretaria Municipal de Educação, a Deus, entre outros.

Ainda sobre os cadernos docentes, encontramos planejamentos de diferentes disciplinas num mesmo suporte: Português, Matemática, Geografia, História, Ciências. Além das disciplinas do núcleo comum, também existem registros de atividades a serem desenvolvidas nas aulas de Educação Física e de Artes. Isso demonstra que em algumas escolas não havia professores específicos para ministrarem esses componentes curriculares, cabendo ao alfabetizador. Já nos cadernos escolares, as atividades registradas se circunscreveram à disciplina de Português ou, em alguns casos, veio associada aos registros matemáticos.

Três dos cadernos discentes trouxeram uma curiosidade que nos ensinou sobre o relacionamento das crianças com as mães. Na contracapa do caderno, a mãe escreveu uma declaração para o filho: "Christony mamãe te ama muitão" 26/08/08 que foi rodeada por um coração, sugerindo uma forte ligação afetiva entre o locutor e o destinatário. Em resposta, localizamos, na última página do segundo caderno que esse mesmo aluno utilizou durante o ano letivo de 2008, a seguinte mensagem: 01/10/2008 "Mamãe tianmo munto do tamanho do meu coração Bejos", dentro de um coração que continha a imagem de uma boca, sugerindo a representação dos beijos que o filho gostaria de dar em sua mãe e, ainda, o desenho de duas pessoas que representa ele com a mãe, pois escreveu acima das figuras: "EU VOCÈ”.

Na contracapa do caderno de Mariana também encontramos uma declaração de amor que a menina escreveu para sua mãe: “AMO MINHA MÃE PARA SEMPRE NO FUNDO DO MEU CORAÇÃO MÂE", acompanhada da imagem que fazia de sua mãe cabelos longos com franjas e presos, usando vestido de alças com um par de botas, braços levantados e abertos com um sorriso nos lábios.

Se pensarmos na relação entre o projeto discursivo escrito e o imagético do texto produzido pela aluna da $1^{\text {a }}$ série, é possível afirmar que estava carregada de um tom emocional-volitivo porque numa tentativa de encurtar a passagem cronológica do tempo, proveniente dos momentos em que se encontrava na instituição escolar, por conseguinte, distante da sua casa e, em especial, da sua mãe, a menina registrou o que 
sentia. Portanto, sua escrita foi permeada por sentimentos, desejos e seu desenho complementou a entonação expressiva do enunciado: o sorriso nos lábios da mãe, podendo representar a alegria do reencontro; os braços levantados e abertos para abraçar a filha assim que retornasse ao lar; e, a flor que nos remete à ideia do galanteio. No dizer de Bakhtin (2003, p. 289) é o elemento expressivo que dá o colorido emocional ao enunciado, ou seja, a

[...] relação subjetiva emocionalmente valorativa do falante com o conteúdo do objeto e do sentido do seu enunciado. Nos diferentes campos da comunicação discursiva, o elemento expressivo tem significado vário e grau vário de força, mas ele existe em toda parte: um enunciado absolutamente neutro é impossível.

Naquela ocasião, Mariana escreveu para uma interlocutora determinada - sua mãe, movida por um objetivo interno bem definido - expressar o que sentia pela mãe, a respeito de um assunto de interesse familiar - o amor entre mãe e filha, envolvendo certo gênero. Essa escrita livre, sem um direcionamento da professora, na contracapa de seu caderno, sinaliza que a criança sabia dizer por meio da escrita o que desejava em determinada situação concreta de comunicação discursiva capaz de balizar o quê, como dizer e para quem o disse. Desse modo, podemos afirmar que seu projeto discursivo se constituiu em um enunciado pleno, pois representou sua posição ativa de falante.

As crianças, ao materializarem seus sentimentos em grafite e papel, deixaram marcas de relações afetivas com as mães, fornecendo pistas que permitem aprender um pouco sobre suas vidas em família. Também nos chamou a atenção o local em que essas enunciações se fixaram: na contracapa ou na última folha, apontando que os alunos e também as mães haviam se apropriado de determinadas regras escolares, por exemplo, as folhas internas dos cadernos são reservadas para a escrita de atividades diárias, direcionadas pela professora.

Não foi somente para as mães que as crianças escreveram mensagens repletas de gestos de amor, também as fizeram para suas professoras alfabetizadoras e muitas docentes colaram essas escritas em seus cadernos de planejamentos, possivelmente, para eternizar demonstrações de afeto e de carinho. Ainda encontramos, no dizer de 
Cunha (2008), objetos-relíquia dentro da página de um caderno diário, como a flor já seca pelo tempo que a professora deve ter recebido de um aluno e a guardou para lembrar-se daquela criança.

\section{Enunciações finais, porém provisórias...}

Retomar o processo de escrituração deste texto significa reafirmar a pertinência de trabalhos com cadernos como fontes históricas para a pesquisa em educação. Para além de atividades circunscritas ao ensino da linguagem escrita, os registros materializados nesses documentos são valiosos para a compreensão de parte das práticas cotidianas vividas em classes de alfabetização de escolas públicas capixabas, tendo em vista que presentificam uma multiplicidade de discursos que nos fornecem indícios de usos e modos como docentes e discentes se inscreveram enquanto usuários desses objetos-memória. Ou seja, obedeciam e/ou burlavam as normas dessa estrutura de registros da escrita escolar engendradas socialmente, usavam, em algumas vezes, de modo peculiar esse suporte material. Assim, foi possível dar visibilidade à parte das relações que se passaram em salas de aula e que ficaram documentadas nessas fontes históricas de pesquisa.

Nossos diálogos com os aspectos físicos (formato, dimensões, disposição dos espaços gráficos etc.), a iconografia (capas, organização interna etc.) e os diferentes modos de usos dos cadernos docentes e discentes que compõem nosso corpus discursivo, permitiram observar que os aprendizes da língua materna escrevem a lápis, muitas vezes, acatando o limite estabelecido pelas margens da página, enquanto as professoras escrevem a lápis e/ou à caneta de cores variadas e nem sempre respeitam a linha vertical da folha; independente do modelo de encadernação, algumas folhas são arrancadas para outros fins; as imagens das capas trazem indícios sobre o sexo dos usuários; a marcação do tempo fez-se presente em todos os cadernos, registrando partes de períodos letivos; nem sempre a mesma docente esteve à frente das atividades, houve marcas de professores substitutos. Por parte das docentes, há uma preocupação com a estética dos cadernos escolares, pois eles permitem aos pais e/ou responsáveis acompanhar a sequência de trabalhos desenvolvidos em salas de aula. 
Ainda foi possível entrever o uso dos cadernos discentes como meio de diálogos entre a escola e a família e vice-versa; como suportes físicos de outros papéis, por exemplo, as folhinhas mimeografadas e/ou xerocopiadas. As marcas de correção das atividades realizadas apontaram para mensagens de elogios aos alunos, de recomendações e de comprovação da revisão feita, permitindo aos pais acompanharem o desenvolvimento acadêmico dos filhos. Nas páginas de cadernos diários foi possível evidenciar que os professores escrevem diariamente, mesmo que não seja com a finalidade de publicação, mas planejam e registram aulas, lembretes, bilhetes, acontecimentos locais, desempenhos de alunos, atas de reuniões de pais, tensões e dilemas do contexto escolar, desabafos, súplicas, entre outras escritas. Enfim, há uma diversidade de registros nos cadernos que abre várias possibilidades de utilização desses objetos-memória aos pesquisadores.

Indubitavelmente, nessa tentativa de desinvisibilizar os cadernos, deixamos muitas questões de fora, até porque tudo depende "[...] da posição que adota aquele que olha. O lugar de onde se olha condiciona não somente o que se vê, mas também como se vê e o que se vê" (VIÑAO, 2008, p. 15). Ainda assim, pensamos estar claro o que pretendíamos apresentar - não há discurso fora do suporte físico que o dá a ler, por conseguinte, o entendimento de discursos sobre práticas alfabetizadoras também depende dos modos por meio dos quais eles chegam ao pesquisador. 


\section{Referências}

BAKHTIN, Mikhail Mikhailovith. Estética da criação verbal. São Paulo: Martins Fontes, 2003.

BAKHTIN, Mikhail Mikhailovith; VOLOCHÍNOV, Valentin. Marxismo e filosofia da linguagem. São Paulo: Hucitec, 2004.

BRAVO, ZEAN. Cadernos para todos os momentos. Papel \& Arte, ano 4, n. 19, p. 34-35, abr./maio, 1997

CHARTIER, Anne-Marie. Os cadernos escolares: organizar os saberes, escrevendo-os. Revista de Educação Pública. Cuiabá, v. 16, n. 32, p. 13-34, set./dez. 2007.

CUNHA, Maria Teresa Santos. Territórios abertos para a História. In: PINSKY, C. B.; LUCA, T. R. (Orgs.). O historiador e suas fontes. São Paulo: Contexto, 2009. p. 251-279.

GVIRTZ, Silvina. El discurso escolar a través de los cuadernos de clase. Buenos Aires: Eudeba, 1999.

HÉBRARD, Jean. Por uma bibliografia material das escritas ordinárias: o espaço gráfico do caderno escolar (França - séculos XIX-XX). In: Revista Brasileira de História da Educação. Campinas, n. 1, p. 115-141, jan./jun. 2001.

LOPES, Isa Cristina da Rocha. Cadernos escolares: memória e discurso em marcas de correção. In: MIGNOT, Ana Chrystina Venancio V. (Org.). Cadernos à vista: escola, memória e cultura escrita. Rio de Janeiro: EdUERJ, 2008. p. 187-204.

MIGNOT, Ana Chrystina Venancio. Do primeiro rabisco até o be-a-bá. In: III CONGRESSO INTERNACIONAL SOBRE PESQUISA (AUTO)BIOGRÁFICA. Natal, 2008.Catálogo da exposição “Não me esqueça num canto qualquer". Natal: FAPERJ, 2008.

MIGNOT, Ana Chrystina Venancio. Cadernos à vista: escola, memória e cultura escrita. Rio de Janeiro: EDUERJ, 2008a.

MIGNOT, Ana Chrystina Venancio. Janelas indiscretas: os cadernos escolares na historiografia da educação. In: VIDAL, Diana Gonçalves; SCHWARTZ, Cleonara Maria História das culturas escolares no Brasil. Vitória: EDUFES, 2010, p. 425-446.

MIGNOT, Ana Chrystina Venancio; CUNHA, Maria Teresa Santos. Razões para guardar: a escrita ordinária em arquivos de professores/as. In: Revista Educação em Questão. Natal, v. 25, n. 11, p. 40-61, jan./abr. 2006.

SANTOS, Anabela Almeida Costa. Aprendendo a usar cadernos: um caminho necessário para a inserção na cultura escolar. In: MIGNOT, Ana Chrystina Venancio. (Org.). Cadernos à vista: escola, memória e cultura escrita. Rio de Janeiro: EdUERJ, 2008. p. 145-160. 
SANTOS, Vera Mendes dos. Nascimento dos cadernos escolares: um dispositivo de muitas faces. 2002. 134f. Dissertação (Mestrado em Educação e Cultura) - Universidade do Estado de Santa Catarina, Florianópolis, 2002.

VIDAL, Diana. Gonçalves. Fim do mundo do fim: avaliação, preservação e descarte documental. In: FARIA FILHO, Luciano Mendes (org.). Arquivos, fontes e novas tecnologias: questões para a história da educação. Campinas, SP: Autores Associados; Bragança Paulista, SP: Universidade São Francisco, 2000.

VIÑAO, Antonio. Os cadernos escolares como fonte histórica: aspectos metodológicos e historiográficos. In: MIGNOT, Ana Chrystina Venancio. (Org.). Cadernos à vista: escola, memória e cultura escrita. Rio de Janeiro: EdUERJ, 2008. p. 15-33. 